\title{
Effect of Berkefeld filtration on the binding activity of human gastric juice
}

\author{
A. W. DEllipiani, R. R. SAMSON, AND R. H. GIRDWOOD \\ From the Gastrointestinal Unit of the University Department of Therapeutics at \\ The Royal Infirmary, Edinburgh
}

SYNOPSIS The intrinsic factor content of Berkefeld-filtered human gastric juice has been studiedis This appears to vary with the $p \mathbf{H}$ at which filtration is carried out and also between individuat filters. Significant losses of intrinsic factor may result from filtration and complete loss when fil- $\vec{\sigma}$ tration is carried out at a low $p \mathrm{H}$. The most suitable $p \mathrm{H}$ for filtration appears to be in the range $p \mathrm{H} 7$ to 8 .

It is known that filtration of human gastric juice through a Seitz filter causes it to lose intrinsic factor activity while Berkefeld filtration is said not to do this (Taylor, Castle, Heinle, and Adams, 1938; Hall, Morgan, and Campbell, 1949; Ungley, 1950) but there is little recent information on this subject (Glass, 1963). During work involving the study of the uptake of vitamin $B_{12}$ by microorganisms in the presence of gastric juice, the problem of sterilizing the juice was encountered. This prompted further study of the effect of Berkefeld filtration on the binding activity of gastric juice, particularly after it was noted that after filtration the binding activity of gastric juice tended to be somewhat variable.

\section{METHODS}

Cultures of $E$. coli were prepared by inoculating $1 \mathrm{ml}$ of an overnight culture into $10 \mathrm{ml}$ DIFCO microinoculum broth at room temperature. Cyanocobalamin was added to the cultures at room temperature in $0.1 \mathrm{ml}$ water. The ${ }^{58}$ cobalt-labelled vitamin was obtained from the Radiochemical Centre, Amersham, as ampoules containing $3.6 \mu \mathrm{g}$ and activity $10 \mu \mathrm{c}$. To these $6.4 \mu \mathrm{g}$ of the stable vitamin was added and the volume made up to $15 \mathrm{ml}$ with sterile water. Thus $0 \cdot 1 \mathrm{ml}$ water would contain $1 / 15 \mu \mathrm{g}$ cyanocobalamin with activity $1 / 15 \mu \mathrm{c}$. This is approximately 12 times the amount of vitamin in $10 \mathrm{ml}$ DIFCO broth. The uptake of the labelled vitamin by the microorganisms was determined after a further period of incubation for 16 hours at $37^{\circ} \mathrm{C}$ and at $p \mathrm{H} \mathrm{6.8.} \mathrm{The}$ cultures were then centrifuged at 3,000 revolutions per minute for 30 minutes and the radioactivity of the supernatant was calculated using a well type scintillation counter. By comparing this with the activity of uninoculated controls the uptake of the labelled vitamin by the microorganisms was calculated.

Received for publication 13 June 1968.
By combining measured volumes of human gastric juice with the cultures the uptake of vitamin $B_{12}$ by the organisms in the presence of gastric juice was deter $\overrightarrow{0}$ mined. Gastric juice was obtained from subjects aftero augmented histamine stimulation (Kay, 1953; Card Marks, and Sircus, 1955) and the pepsin in this inactivatedo by alkaline denaturation (Grassbeck, 1960). It was then kept at $-20^{\circ} \mathrm{C}$ until required. Only juice from patientso with an output of more than $20 \mathrm{~m}$-equiv acid in the post histamine hour or of known intrinsic factor concentratiorb was used. The latter was measured by the method of Ardeman and Chanarin (1963).

Crystalline pepsin (Worthington USA) was added as $2.5 \mathrm{mg}$ in $0.1 \mathrm{ml}$ of water per millilitre of gastric juice This concentration of enzyme is based on observations made on the concentration of pepsin in human gastricos juice (Babkin, 1950; Reizenstein, 1959). Enzyme digestion was carried out for four hours at $p \mathrm{H} 2$ and after this period the enzyme was inactivated by alkaline denaturation.

Appropriate controls were set up throughout and particular care was taken to detect bacterial contamination of the various solutions employed. All experiments were carried out in duplicate, the measure of agreement between duplicate samples being excellent.

For the filtration work six new standard filter candle (British Berkefeld Filters Ltd, No. 8) were used. Thero were prepared and cleaned for the experiments as inf structed by the makers by boiling in water for 20 minutesค They were then autoclaved at $15 \mathrm{lb}$ pressure for 100 minutes. In each filtration experiment $60 \mathrm{ml}$ of juice wa? passed through the filters under identical conditions.

RESULTS

In Table 1 are illustrated the results of the bacteria采 uptake studies in the presence of increasing volumes of gastric juice which had been filtered at $p \mathrm{H}$ compared with the uptakes in the presence of ung filtered juice. The uptakes in the presence of filteres 


\section{TABLE I}

PERCENTAGE OF UPTAKE OF LABELLED CYANOCOBALAMIN BY $E$. coli IN THE PRESENCE OF INCREASING VOLUMES OF UNFILTERED GASTRIC JUICE AND OF JUICE FILTERED AT $p \mathrm{H} 7$

\begin{tabular}{|c|c|c|}
\hline \multirow[b]{2}{*}{$\begin{array}{l}\text { Volume of Gastric } \\
\text { Juice Added }(\mathrm{ml})\end{array}$} & \multicolumn{2}{|c|}{ Percentage Uptake of Radioactivity } \\
\hline & $\begin{array}{l}\text { Gastric Juice } \\
\text { Filtered at } \mathrm{pH} 7\end{array}$ & Unfiltered Gastric Juice \\
\hline 0 & 93.0 & 93.0 \\
\hline 2 & $18 \cdot 0$ & 12.0 \\
\hline 6 & 11.0 & 10.0 \\
\hline 10 & $10 \cdot 0$ & $7 \cdot 0$ \\
\hline
\end{tabular}

juice are slightly higher, and, though the differences are small, they are reproducible. From Table II it will be seen that the binding activity of gastric juice was more susceptible to peptic digestion after it had been filtered. In Table III it will be seen from the uptake studies that the loss of binding activity becomes more pronounced as the $p \mathrm{H}$ at which the juice is filtered is dropped.

\section{TABLE II}

PERCENTAGE UPTAKE OF LABELLED CYANOCOBALAMIN BY $E$. coli IN THE PRESENCE OF GASTRIC JUICE EXPOSED TO PEPTIC DIGESTION BEFORE AND AFTER FILTRATION

\begin{tabular}{|c|c|c|}
\hline \multirow[b]{2}{*}{$\begin{array}{l}\text { Volume of Gastric } \\
\text { Juice Added }(\mathrm{ml})\end{array}$} & \multicolumn{2}{|c|}{ Percentage Uptake of Radioactivity } \\
\hline & $\begin{array}{l}\text { Gastric Juice Exposed } \\
\text { to Peptic Digestion } \\
\text { for } 4 \text { Hours before } \\
\text { Filtration at } \mathrm{pH} 7\end{array}$ & $\begin{array}{l}\text { Gastric Juice Exposed } \\
\text { to Peptic Digestion } \\
\text { for } 4 \text { Hours after } \\
\text { Filtration at } \mathrm{pH} 7\end{array}$ \\
\hline $\mathbf{0}$ & $84 \cdot 0$ & $84 \cdot 0$ \\
\hline 2 & $33 \cdot 5$ & 53.9 \\
\hline 6 & $4 \cdot 5$ & $17 \cdot 5$ \\
\hline 10 & $3 \cdot 1$ & $8 \cdot 3$ \\
\hline
\end{tabular}

Figure 1 shows the results of an experiment in which intrinsic factor determinations were made on the gastric juice before and after filtration, the $p \mathrm{H}$ of the juice being altered in the range $p \mathrm{H} 6$ to 10 before filtration. The intrinsic factor concentration of the juice before filtration was $65.6 \mathrm{ng} / \mathrm{ml}$. Figure 2 illustrates the results of similar experiments, filtration being carried out at different $p \mathrm{H}$ values through three of the same filters used above. A different pool of gastric juice (intrinsic factor concentration 50.7 $\mathrm{ng} / \mathrm{ml}$ ) was employed on this occasion. These figures

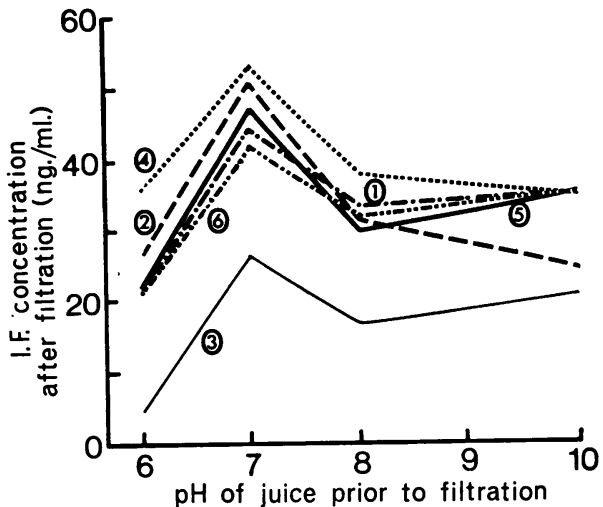

FIG. 1. Effect of Berkefeld filtration of human gastric juice at $\mathrm{pH}$ 6-10. The intrinsic factor content of the juice was $65.6 \mathrm{ng} / \mathrm{ml}$. The circled figures refer to the number allocated to the filter.

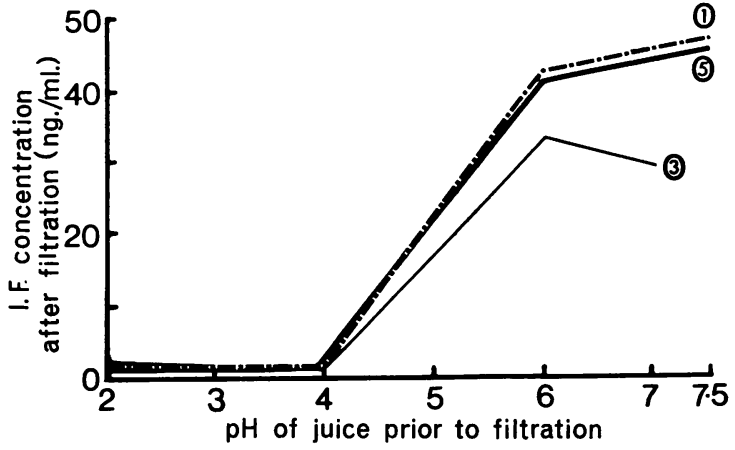

FIG. 2. Effect of Berkefeld filtration of human gastric juice at $\mathrm{pH} 2-7$. The intrinsic factor content of the juice was $50.7 \mathrm{ng} / \mathrm{ml}$. The circled figures refer to the number allocated to the filter.

on the whole confirm the observations made in the vitamin $B_{12}$ uptake experiments and indicate that the loss of binding activity noted there was due to loss of intrinsic factor activity.

\section{DISCUSSION}

The findings confirm the claim of previous workers

TABLE III

PERCENTAGe UPTAKe OF LABELled CYANOCOBALAMIN BY $E$. coli IN THE PRESENCE OF INCREASING VOLUMES OF GASTRIC JUICE FILTERED AT DIFFERENT $p H$ VALUES

Percentage Uptake of Radioactivity in Gastric Juice Filtered at Various $\mathrm{pH}$ Values

\begin{tabular}{|c|c|c|c|c|c|c|}
\hline \multirow[b]{2}{*}{ Volume of Gastric Juice Added $(\mathrm{ml})$} & \\
\hline & $\mathrm{p} H 2$ & $\mathrm{p} H 4$ & $\mathrm{pH} 6$ & $\mathrm{p} H 7$ & $\mathrm{p} H 8$ & $\mathrm{pH} 10$ \\
\hline $\begin{array}{r}0 \\
2 \\
6 \\
10\end{array}$ & $\begin{array}{l}90.9 \\
89.0 \\
84.0 \\
81.0\end{array}$ & $\begin{array}{l}90 \cdot 9 \\
80 \cdot 8 \\
64 \cdot 3 \\
54 \cdot 9\end{array}$ & $\begin{array}{r}90.9 \\
20.0 \\
8.0 \\
6.0\end{array}$ & $\begin{array}{r}90.9 \\
16.0 \\
7.5 \\
2.4\end{array}$ & $\begin{array}{r}90.9 \\
12.8 \\
7.8 \\
6.4\end{array}$ & $\begin{array}{r}90.9 \\
13.5 \\
5.2 \\
3.1\end{array}$ \\
\hline
\end{tabular}


in that gastric juice which has been filtered through a Berkefeld filter still contains intrinsic factor. This, however, is true mainly of juice filtered in the $p \mathrm{H}$ range 7 to 8. At $p \mathrm{H}$ values above and below this range there tends to be some loss of intrinsic factor activity and this is complete in the lower $p \mathrm{H}$ range. It should be recalled here that intrinsic factor is known to be stable up to a $p \mathrm{H}$ of 11.5 (Glass, 1963). We have carried out numerous experiments similar to those illustrated in Figs. 1 and 2 and the results confirm the impression gained from these that there is considerable variability in the concentrations of intrinsic factor that different filters will allow through. In addition, in spite of our attempts to standardize experimental conditions, there has been some variation between results obtained after filtering the same gastric juice through the same filter on different occasions. Further work, which has included the use of other filters, leaves us in no doubt, however, that certain filters, such as no. 3 in the present study, may remove considerable quantities of intrinsic factor even if filtration is performed in the more favourable $p \mathrm{H}$ range.

The manner by which the filters bring about their effect is puzzling but an important clue may be contained in the observations made on the $p \mathrm{H}$ of the filtrate. This tends towards neutrality regardless of the $p \mathrm{H}$ of the juice before filtration. Thus when juice is filtered at $p \mathrm{H} 2$ the $p \mathrm{H}$ of the effluent has changed to between 7 and 8 . The application of negative pressure to the filters has not significantly affected the results obtained and it has not been possible to wash the intrinsic factor presumably left behind out of the filters through which juice has been passed at low $p \mathrm{H}$ with either alkali or water. Prolonging the period of filtration does not result in any significant change in the intrinsic factor concentrations of the filtered juice though the intrinsic factor content of $\frac{\mathrm{O}}{\mathrm{N}}$ initial aliquots of juice even when filtered at $p \mathrm{H} 7 \overrightarrow{\overrightarrow{\vec{A}}}$ may be very low.

Gastric juice is sometimes used as a source of intrinsic factor in tests of vitamin $\mathbf{B}_{12}$ absorption $\frac{\bar{c}}{\bar{c}}$ and Berkefeld filtration is a popular method of preparing it for this procedure (Taylor et al, 1938; Hall et al, 1949; Ungley, 1950). The present work suggests that occasionally this could lead to er- $\vec{\circ}$ roneous results. Thus $50 \mathrm{ml}$ of gastric juice of intrinsic factor content $65.6 \mu \mathrm{g} / \mathrm{ml}$ if passed through the $\omega^{\omega}$ worst of our filters at $p \mathrm{H} 7$ would still contain $890 \mathrm{ng}$ of intrinsic factor. This would usually be enough to correct impaired absorption of vitamin $B_{12}$ in aN patient with pernicious anaemia though more might? be required in a patient with deficiency of intrinsic $\vec{\sigma}$ factor after gastric surgery (Ardeman and Chanarin, $N$ 1965). Error would of course be more likely if juice of a lower intrinsic factor concentration was being $\overrightarrow{\vec{z}}$ filtered. The effect of Berkefeld filtration on gastric juice in more subtle work certainly cannot be dis- $\frac{\widehat{S}}{\supset}$ regarded and consequently its use in the uptake studies described had to be abandoned.

\section{REFERENCES}

Ardeman, S., and Chanarin, I. (1963). Lancet, 2, 1350. (1965). Brit. J. Haemat., 11, 305.

Babkin, B. P. (1950). Secretory Mechanism of the Digestive Glands, $\mathbb{D}$ 2nd. ed. Hoeber, New York.

Card, W. I., Marks, I. N., and Sircus, W. (1955). J. Physiol. (Lond.), $\overline{\bar{O}}$ 130, $18 P$.

Glass, G. B. J. (1963). Physiol. Rev., 43, 529.

Grassbeck, R. (1960). Advanc. clin. Chem., 3, 299.

Hall, B. E., Morgan, E. H., and Campbell, D. C. (1949). Proc. Mayo Clin., 24, 99.

Kay, A. W. (1953). Brit. med. J., 2, 77.

Reizenstein, P. G. (1959). Acta med. scand., 165, 481.

Taylor, F. H. L., Castle, W. B., Heinle, R. W., and Adams, M. A. (1938). J. clin. Invest., 17, 335.

Ungley, C. C. (1950). Brit. med. J., 2, 908. 